\title{
Long-Term Outcomes of Holmium Laser Enucleation of the Prostate: A 5-Year Single-Center Experience
}

\author{
Dmitry Enikeev, MD, ${ }^{1}$ Mark Taratkin, MD, ${ }^{1}$ Andrey Morozov, MD, ${ }^{1}$ Nirmish Singla, MD, ${ }^{2}$ Svetlana Gabdulina, ${ }^{3}$ \\ Alexander Tarasov, ${ }^{3}$ Roman Sukhanov, MD, Juan Gomez Rivas, MD, ${ }^{4}$ Ekaterina Laukhtina, MD, \\ Magomed Arshiev, ${ }^{5}$ Vasiliy Mikhailov, MD, ${ }^{1}$ and Petr Glybochko, MD ${ }^{1}$
}

\begin{abstract}
Objective: To analyze the long-term efficacy and safety of holmium laser enucleation of the prostate (HoLEP) for benign prostatic hyperplasia.

Materials and Methods: A total of 127 patients who underwent HoLEP at our institution between 2013 and 2015 were included. Patients were observed for 5 years postoperatively. We evaluated the length of the surgery, the mass of the removed tissue, prostate-specific antigen level, the maximal flow rate (Qmax), postvoid residual (PVR), the length of catheterization and hospitalization, and the International Prostate Symptom Score (IPSS) and IPSS quality of life (QoL) at each clinic visit.

Results: PVR, Qmax, IPSS, and QoL all improved significantly immediately after the operation $(p<0.001)$. By the end of the 5th postoperative year, all the parameters showed a statistically meaningful decline: Qmax reduced by $5.8 \mathrm{~mL} / \mathrm{s}(22.6 \%)$ and IPSS by 1.4 points $(29.1 \%)$. Around $8.6 \%$ of the patients continued therapy with $\alpha$-blockers. There were no differences in efficacy by the age of the patients or the volume of the prostate. Longterm complications and need for repeat operations were not affected by the volume of the prostate or patient age. Conclusions: The improvement of PVR, Qmax, IPSS, and QoL score seen in the early postoperative period after performing HoLEP remains evident at 5 years postoperatively. Long-term complications and the need for reoperation do not depend on the age of the patient or on the initial volume of the prostate.
\end{abstract}

Keywords: BPH, HoLEP, EEP, long-term

\section{Introduction}

$\mathbf{T}$

The EFFICACY OF HOLMIUM LASER ENUCLEATION OF THE PROSTATE (HoLEP) in treating benign prostatic hyperplasia (BPH), first described by Fraundorfer and Gilling ${ }^{1}$ over 20 years ago, has been shown in several systematic reviews and meta-analyses. ${ }^{2,3}$ Laser enucleation has become accepted as a gold standard for treating prostates $>80 \mathrm{cc}$ in size. ${ }^{4,5}$ Cornu and colleagues, ${ }^{6}$ in their work examining different methods of treating $\mathrm{BPH}$ (including HoLEP), revealed promising outcomes after HoLEP in both short-term (up to 1 year) and mid-term ( $<5$ years) observation periods. A few years ago, Herrmann T. suggested standardizing the terminology of laser enucleation by introducing the abbreviation endoscopic enucleation of the prostate (EEP). ${ }^{7}$. In that way, he proposed to switch from focusing on the source of power used for the surgery to concentrating on the principle of complete and anatomically correct removal of the prostate. Later, similar efficacy of various types of EEP was shown along with the efficacy of various approaches (2-lobe, 3-lobe, en bloc). ${ }^{8}$

The main intent of EEP is complete removal of the hyperplastic tissue of the prostate along the prostate capsule ${ }^{9}$; if tissue stays on the surgical capsule, there is a higher probability of recurrence, which is an important metric for EEP efficacy. The aim of our work is to analyze the long-term efficacy and safety of HoLEP for BPH.

\footnotetext{
${ }^{1}$ Institute for Urology and Reproductive Health, Sechenov University, Moscow, Russia.

${ }^{2}$ Department of Urology, University of Texas Southwestern Medical Center, Dallas, Texas, USA.

${ }^{3}$ Institute of Linguistics and Intercultural Communication, Sechenov University, Moscow, Russia.

${ }^{4}$ Department of Urology, La Paz University Hospital, Madrid, Spain.

${ }^{5}$ Sechenov University, Moscow, Russia.
} 


\section{Materials and Methods}

We retrospectively analyzed patients who underwent HoLEP between 2013 and 2015. The inclusion criteria for the patients were as follows: moderate-to-severe lower urinary tract symptoms (LUTS) - International Prostate Symptom Score (IPSS) $>20$ points or the maximal flow rate (Qmax) $<15 \mathrm{~mL} / \mathrm{sec}$. The exclusion criteria included prostate cancer or history of surgical procedures in the lower urinary tract, and acute urinary retention or previously placed urinary catheter. Also we excluded patients with incidental prostate cancer, because during 5-year follow-up they underwent either follow-up biopsies of some active treatment, which might bias the urination quality or complication rate.

The functional parameters were measured preoperatively and postoperatively at 1 month, 1 year, 3 years, and 5 years. The results were defined according to the following parameters: IPSS and quality of life (QoL), Qmax, and postvoid residual (PVR). The prostatic volume (V) by transrectal ultrasound and the prostate-specific antigen (PSA) level were measured before and after the surgery. The complications were classified according to Clavien-Dindo grading system. Stress urinary incontinence (SUI) was defined as a necessity to use more than a safety pad per day.

To evaluate the influence of prostate volume on the treatment outcomes, the patients were divided into two groups: V of 30 to $79 \mathrm{cc}$ and $\mathrm{V}$ over $80 \mathrm{~cm}^{3}$, according to previously defined threshold values. ${ }^{4}$ The correlation between patient age and treatment outcomes was also evaluated by stratifying patients into two groups: under 65 years old and over 65 years old (according to World Health Organization ${ }^{10}$ ).

All the operations were performed by three surgeons specializing in BPH surgery and experienced in performing laser enucleation (over 100 surgeries ${ }^{11}$ ). The equipment used was: 100-W holmium laser Versapulse (Lumenis, Inc., Santa Clara, CA/Yokneam, Israel) with a wavelength of 2.1 mcm; 550-mcm laser fiber SlimLineTM550 (Lumenis, Inc., San Jose, CA); resectoscope no. 26 Ch (of Iglesias type); and the working element with the channel for installation of laser fiber. The operation was performed at laser output power of $60 \mathrm{~W}$; during incision within the area of the verumontanum, the power was reduced to $30 \mathrm{~W}$. Adenomatous tissue was morcellated with the Lumenis ${ }^{\circledR}$ VersaCut ${ }^{\mathrm{TM}}$ Morcellator (Lumenis, Inc., Yokneam, Israel), performed with a $5 \mathrm{~mm}$ working channel diameter.

For performing the HoLEP, 2-lobe and 3-lobe techniques were used, as previously described. ${ }^{12}$ Briefly, with the threelobe technique, primary incisions as deep as the prostate capsule are made from the neck of the bladder at 5 and 7 o'clock position; when applying the two-lobe technique, we start the incision at the 6 o'clock position. First, the left lobe is enucleated by incising from 5 to 2 o'clock. Next, the incision is made at 12 o'clock up to the verumontanum. Having connected the incisions at 2 and 1 o'clock, the left lobe is enucleated into the bladder. The right lobe is removed in a similar manner. The excised tissue is then morcellated and removed.

Statistical analysis was performed using SPSS version 23 (IBM Corp, Armonk, NY). The Student's $t$-test was used to determine statistical differences of the independent parameters of the groups. For comparison of means, an analysis of variance test was employed. To estimate correlation between nonparametric values Spearmen criteria were used. Data were expressed as mean \pm standard deviation. A $p$-value of $<0.05$ was considered to indicate statistical significance.

\section{Results}

There were 347 HoLEPs performed at our institution between 2013 and 2015. Exclusions included those whose primary data were missing or those whose postoperative examination data were missing (up to 1 year)—94 patients; those who did not meet the inclusion/exclusion criteria -45 patients; and those who refused or were not able to take part in the surgery-81 patients. The remaining 127 patients were included in our final cohort.

Preoperative and postoperative parameters are represented in Table 1. The mean prostatic volume was $88.6 \pm 43.1 \mathrm{cc}$ (range $30-250 \mathrm{cc})$. Fifty-nine $(46.4 \%)$ patients had prostatic volume $<80 \mathrm{cc}$, whereas $68(53.6 \%)$ patients had prostatic volume over $80 \mathrm{cc}$. The mean age of the patients was $69.6 \pm 7.3$ (range 52-83) years, with $57(44.9 \%)$ patients under 65 years and 70 $(55.1 \%)$ patients over 65 years. The mean PSA level before the operation was $4.9 \pm 3.0$ (range $0.7-14.7$ ) ng/mL. The evaluation of the functional parameters was made with IPSS and QoL scales, which were mean 22.0 \pm 1.1 (range 20-24) and 4.0 \pm 0.9 (range 3-6) points, respectively, preoperatively. PVR volume

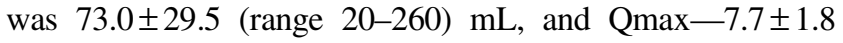
(range 2.4-15.0) $\mathrm{mL} / \mathrm{sec}$.

The mean operation time was $52.9 \pm 10.0$ (range 24-75) minutes, whereas the mean mass of the enucleated tissue was 81.5 (range 25-198) groups. The mean duration of catheterization after the surgery was $1.3 \pm 0.6$ (range 1-3) days, and the duration of hospitalization was $3.3 \pm 0.6$ (range 3-5) days. All the patients showed statistically significant improvement in the functional tests $(p<0.001)$.

Mean follow-up was about 66 months (40-73 moths). After 1 month, 1 year, 3 years, and 5 years upon performing HoLEP, mean PVR was 17.6, 25.2, 31.4, and $34.1 \mathrm{~mL}$, respectively; mean Qmax -16.1, 25.6, 21.8, and 19.8 mL/sec; IPSS-4.9, 5.1, 5.9, and 6.2; and QoL-1.8, 1.1, 1.6, and 1.7 points, respectively (Table 2 ). The dynamics of these parameters depending on the size of the prostate and the patients' age are demonstrated in Figure 1. Despite the gradual

\section{Table 1. Pre- and Perioperative Parameters}

\begin{tabular}{lc}
\hline Parameters & Mean $\pm S D$ (range) \\
\hline Patient's age, years & $66.6 \pm 7.3(52-83)$ \\
PSA, ng/mL & $4.9 \pm 3.0(0.7-14.7)$ \\
V, cc & $88.6 \pm 43.1(30-250)$ \\
PVR, mL & $73.0 \pm 29.5(20-260)$ \\
Qmax, preoperatively, mL/sec & $7.7 \pm 1.8(2.4-15.4)$ \\
IPSS & $22.0 \pm 1.1(20-24)$ \\
QoL & $4.0 \pm 0.9(3-6)$ \\
The length of operative & $52.9 \pm 10.0(24-75)$ \\
intervention, minutes & \\
The mass of the enucleated tissue, gr & $51.5 \pm 13.4(25-78)$ \\
The length of catheterization, days & $1.3 \pm 0.6(1-3)$ \\
The length of hospitalization, days & $3.3 \pm 0.6(3-5)$ \\
\hline
\end{tabular}

IPSS = International Prostate Symptom Score; PSA = prostatespecific antigen; PVR = postvoid residual; Qmax $=\operatorname{maximal}$ flow rate; $\mathrm{QoL}=$ quality of life in connection with the present urination disorders; $\mathrm{SD}=$ standard deviation; $\mathrm{V}=$ prostatic volume. 
Table 2. Postoperative Parameters

\begin{tabular}{|c|c|c|c|c|c|c|c|}
\hline Parameters & $\begin{array}{c}\text { Preoperative } \\
\text { period } \\
(\mathrm{N}=127)\end{array}$ & $\begin{array}{c}1 \text { Year } \\
\text { after the surgery } \\
(\mathrm{N}=127)\end{array}$ & $\begin{array}{c}3 \text { Years } \\
\text { after the surgery } \\
(\mathrm{N}=101)\end{array}$ & $\begin{array}{c}5 \text { Years } \\
\text { after the surgery } \\
(\mathrm{N}=79)\end{array}$ & $\mathrm{p}^{l}$ & $\mathrm{p}^{2}$ & $\mathrm{p}^{3}$ \\
\hline & 14.7) & & 2.2) & $1.6 \pm$ & $<0.001$ & 0.001 & $<0.001$ \\
\hline & & & & & & & \\
\hline PVR, mL & 73.0 & & & & & & $<0.0$ \\
\hline $\begin{array}{l}\text { Qmax, } \\
\mathrm{mL} / \mathrm{sec}\end{array}$ & & $25.6 \pm 6.7(6-35)$ & 2 & $\pm 5.1(5-28)$ & $<0.001$ & $<0.001$ & $<0.0$ \\
\hline IPSS & & & & & & & \\
\hline QoL & $4.0 \pm 0.9(3-6)$ & $1.1 \pm 0.9(0-4)$ & $1.6 \pm 1.2(0-4)$ & $1.7 \pm 1.2(0-5)$ & $<0.001$ & $<0.001$ & $<0.00$ \\
\hline
\end{tabular}

$\mathrm{p}^{1}-\mathrm{p}$-index between the parameters in preoperative and postoperative period ( 1 month).

$\mathrm{p}^{2}-\mathrm{p}$-index between the parameters during 1 st and 3rd year after the surgery.

$\mathrm{p}^{3}-\mathrm{p}$-index between the parameters during the 1 st and 5 th year after the surgery.

reliable degradation of the PVR, Qmax, IPSS, and QoL $(p<0.05)$ at long-term surveillance (upon 5 years after the surgery), their comparison with the preoperative parameters shows that they are much better than the latter and stay within the normal range.

For all patients, we discontinued $\alpha$-blockers immediately after surgery. Subsequently, if a patient had moderate or severe LUTS (specifically irritative symptoms) even after the procedure, drugs were administered. At 5 years' surveillance, $11(8.7 \%)$ patients who underwent HoLEP was taking $\alpha$-blockers for recurrent symptoms. Unfortunately, no data regarding the frequency of $\alpha$-blocker therapy at other time points are available. Measuring Spearman's rank correlation coefficient, we observed that $\alpha$-blocker medication use correlated with the prostatic volume $(r=0.129 ; p=0.025)$ and IPSS results $(r=0.321 ; p=0.002)$ after a 5 -year period of time. Any correlation with the preoperative parameters or age was not identified. Moreover, the prostate volumes at 3 and 5 -year follow-ups and IPSS at 5 years were significantly higher in these patients, than in main group (Table 3). Two of these patients underwent repeated surgery.

Postoperative complications are represented in Table 4. Grade I complications according to Clavien-Dindo classification are: stress incontinence (7 patients, 5.5\%), injury of the bladder wall ( 2 patients, $1.6 \%$ ), and injury of ureteral orifice (1 patient, $0.8 \%$ ). Grade II complications included hyperthermia $>38^{\circ} \mathrm{C}$ and hematuria resulting in clot retention-5 (3.9\%) and $10(7.8 \%)$ patients, respectively. None of the patients required the blood transfusion. Acute urinary retention after the removal of the catheter occurred in $8(6.3 \%)$ patients. Grade IIIb complications were found in 11 (8.6\%) patients: tamponade of the bladder with blood clots requiring cystoscopy with vessel coagulation occurred in $6(4.7 \%)$ patients, and delayed morcellation (due to intraoperative hemorrhage and poor vision) was performed in $5(3.9 \%)$ cases. None of the patients encountered TURP syndrome. No associations of the complication rate with the surgeon were found.

Delayed postoperative complications are presented in Table 5. At 5-year follow-up total number of urethral strictures was 4 (3\%), and bladder neck sclerosis (BNS) occurred total in only $2(1.6 \%)$ patients. The majority of these complications were observed during first 3 years. Since 3 to 5 years follow-up, only 1 additional case of urethral stricture was diagnosed. Due to BPH residual growth, 4 (3\%) patients underwent repeat surgery: only 1 at the 3 -year follow-up, and additional 3 cases occurred from 3 to 5 -year surveillance. The surgery for urethral stricture was cold knife urethrotomy, for BNS-laser incision, and for residual BPH-repeat HoLEP.

\section{Discussion}

We found that the positive outcomes of laser enucleation remain 5 years after performing the surgery. The number of recurrences requiring repeat surgical intervention was not high-only $4(3 \%)$ cases. The parameters of the functional tests decreased in some patients, yet this decrease was not clinically significant. In most of the patients the LUTS severity remain rather same, with only $11(8.7 \%)$ patients who showed mild-to-moderate symptoms (IPSS).

In a meta-analysis, Cornu and colleagues ${ }^{6}$ showed that for recurrences, HoLEP can be compared with the most anatomically correct removal of the adenoma-simple prostatectomy. Therefore, we may assume that this recurrence is due to regrowth of the adenoma nodes, rather than residual tissue. Yet precise pathogenesis of the recurrence is not known. Elkoushy and colleagues ${ }^{13}$ supposed that the recurrence of BPH after HoLEP is associated with the existence of several subcapsular nodes, which begin to grow at some particular moment and cause obstruction. Furthermore, in their study the recurrence was more often observed after surgery for prostates with smaller volumes $(62.4 \pm 21.7 \mathrm{cc} v s 94.6 \pm 53.2 \mathrm{cc}, p=0.006) .{ }^{13}$ We did not find this relationship in our study when stratifying patients by volumes $\leq v s$. $>80 \mathrm{cc}$.

It should be noted that continuation of $\alpha$-blocker medication is mentioned in only few studies. This medication is considered to be the first-line therapy of BPH and is often prescribed even to the patients without acute symptomatology. In our study, the frequency of taking the $\alpha$-blockers after a 5-year time constituted 8.6\%, whereas $122(96.0 \%)$ patients were taking the medication preoperatively. All of these patients were taking drugs for at least 3 months for bothersome symptoms. Among them 2 underwent a repeated surgery at 5 -year follow-up. In a study by Han and colleagues the frequency of taking $\alpha$-blockers exceeded 50\% during the first postoperative year after TURP. ${ }^{14}$ Unfortunately, we did not manage to follow how the frequency of taking the medication changed over time; however, we found that it was not related to the preoperative prostatic volume, IPSS, or the patients' age. The latter is especially significant, since Han and colleagues ${ }^{14}$ demonstrated opposite results: in their work, age 


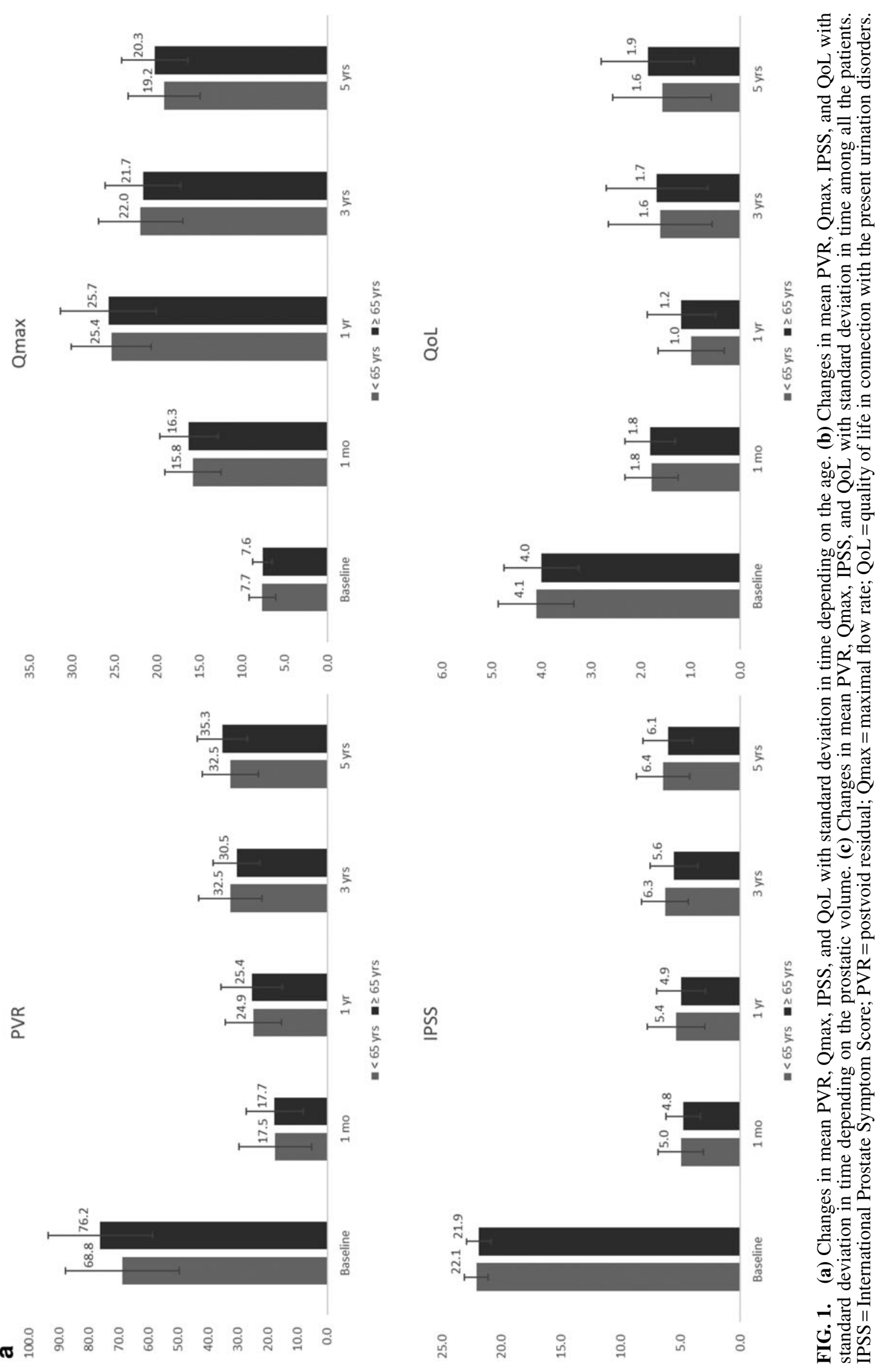



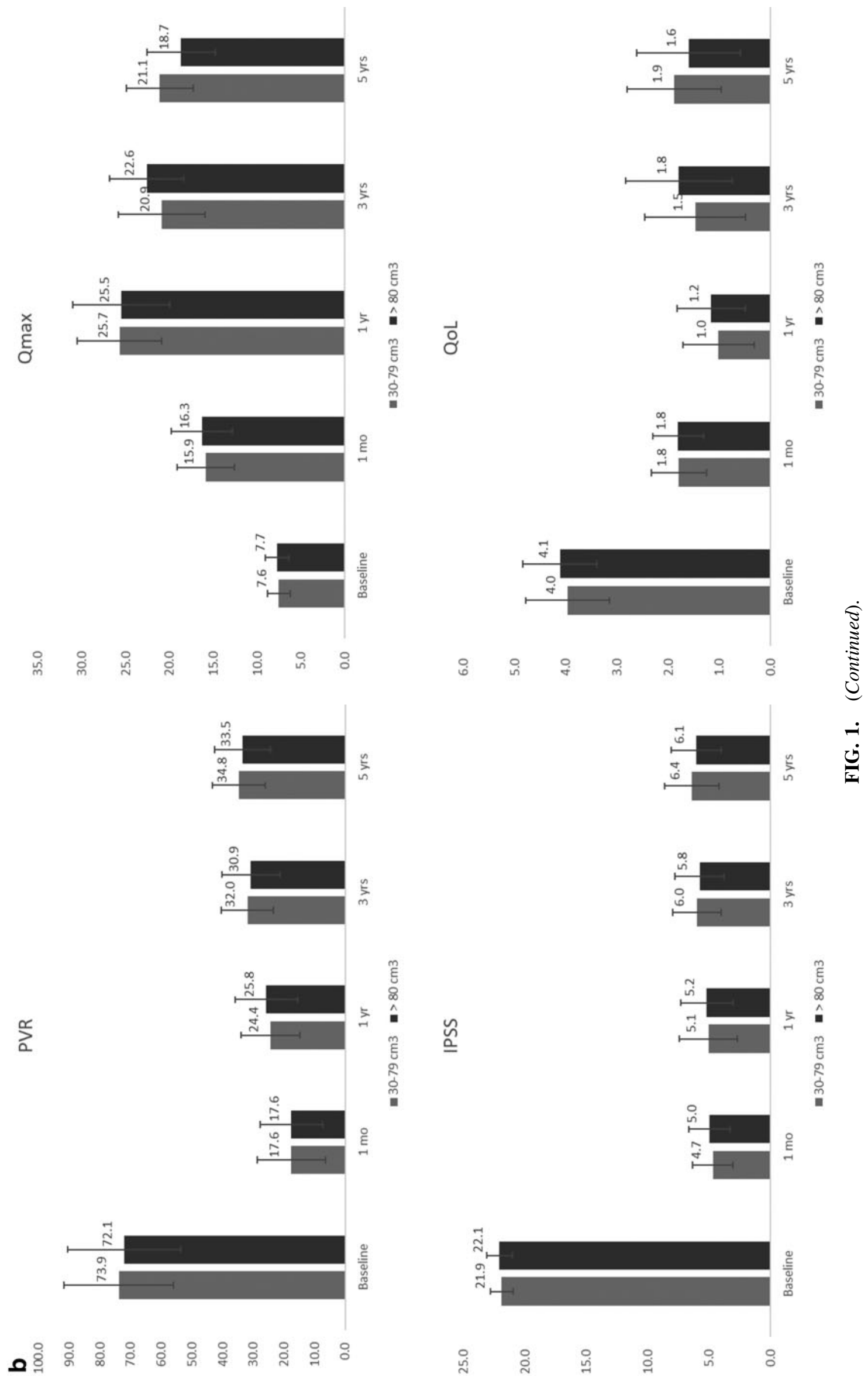

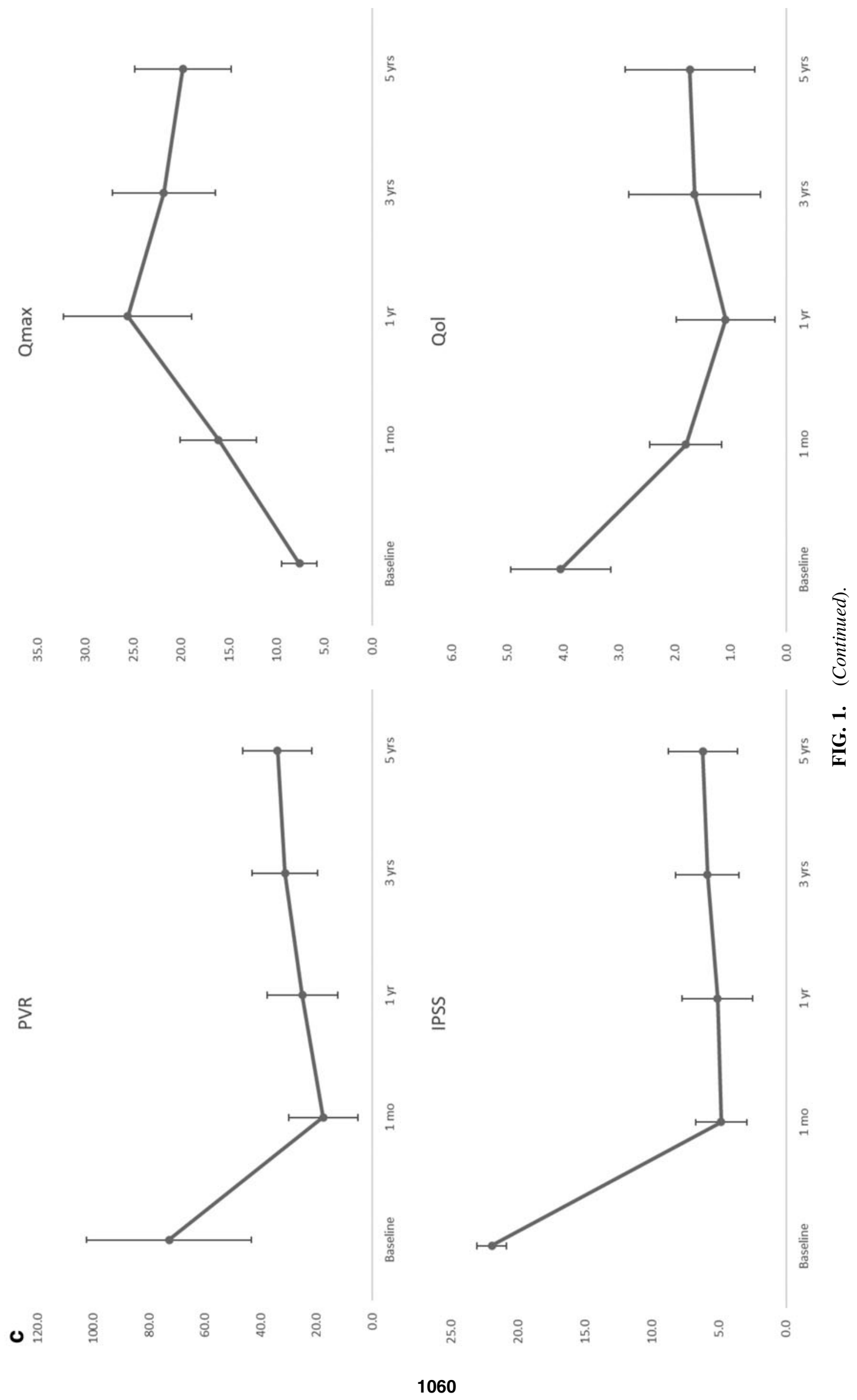
Table 3. Differences in Between Groups of $\alpha$-Blocker Users and Nonusers

\begin{tabular}{|c|c|c|c|}
\hline Parameters & $\begin{array}{l}\text { No } \alpha \text {-blocker therapy } \\
(116 \text { patients, } 91.4 \%)\end{array}$ & $\begin{array}{c}\alpha-\text { Blocker therapy } \\
(11 \text { patients, } 8.6 \%)\end{array}$ & $\mathrm{p}$ \\
\hline Age (years) & $66.4 \pm 7.3$ & $68.8 \pm 7.7$ & 0.303 \\
\hline Preoperative prostate volume (cc) & $89.3 \pm 44.4$ & $81.2 \pm 24.6$ & 0.129 \\
\hline Postoperative prostate volume (cc) & $18.1 \pm 9.0$ & $23.6 \pm 7.7$ & 0.052 \\
\hline Prostate volume at 3-year (cc) & $21.2 \pm 10.5$ & $29.5 \pm 8.7$ & $0.048 *$ \\
\hline Prostate volume at 5-year (cc) & $23.2 \pm 11.6$ & $33.3 \pm 10.8$ & $0.002 *$ \\
\hline PSA (ng/mL) & $4.7 \pm 3.0$ & $6.2 \pm 2.7$ & 0.129 \\
\hline Postoperative PSA (ng/mL) & $1.0 \pm 0.3$ & $0.9 \pm 0.3$ & 0.352 \\
\hline PSA at 3-year (ng/mL) & $1.2 \pm 0.3$ & $1.08 \pm 0.3$ & 0.35 \\
\hline PSA at 5-year (ng/mL) & $1.3 \pm 0.4$ & $1.5 \pm 0.4$ & 0.438 \\
\hline Preoperative IPSS & $22.0 \pm 1.1$ & $22.7 \pm 2.7$ & 0.084 \\
\hline Postoperative IPSS & $4.9 \pm 1.9$ & $4.2 \pm 1.4$ & 0.223 \\
\hline IPSS at 3-year & $5.8 \pm 2.3$ & $6.2 \pm 2.9$ & 0.574 \\
\hline IPSS at 5-year & $6.2 \pm 2.6$ & $9.7 \pm 2.0$ & $0.001 *$ \\
\hline Preoperative Qmax (mL/s) & $7.7+1.8$ & $6.6 \pm 1.3$ & 0.061 \\
\hline Qmax at 1-year $(\mathrm{mL} / \mathrm{s})$ & $25.0 \pm 12.7$ & $26.6 \pm 10.1$ & 0.20 \\
\hline Qmax at 3-year (mL/s) & $21.7 \pm 5.5$ & $22.9 \pm 4.7$ & 0.482 \\
\hline Qmax at 5-year $(\mathrm{mL} / \mathrm{s})$ & $19.8 \pm 5.0$ & $17.3 \pm 4.6$ & 0.122 \\
\hline
\end{tabular}

*Statistically significant $p$-values $(p<0.05)$.

was predictive of continued medication use. The absence of this association in our study may be attributable to the overall elderly age of our cohort ( $\sim 69$ years). An interesting finding was presented by Strope and colleagues ${ }^{15}$ Author queried Truven database for patients who underwent EEP or TURP and assessed the rate of postoperative medication intake. The rate of $\alpha$-blocker usage was $10.3 \%$ for EEP and $9.0 \%$ for TURP, the total rate of postoperative drug usage due to bothersome symptoms was $25.3 \%$ and $21.2 \% .^{15}$ Authors were able to prove that, if patient used drugs before surgery, the possibility for their repeat use is increased. Unfortunately, more than $96 \%$ of patients in our study were taking drugs preoperatively, therefore, we were unable to analyze the frequency of it is repeat use.

For long-term safety assessment we reported rates of urethral stricture and cicatricial deformity of the bladder

Table 4. Early Postoperative Complications According to Clavien-Dindo Classification

\begin{tabular}{lc} 
Type of complication & Quantity-absolute, $\mathrm{n}(\%)$ \\
\hline Grade I & $7(5.5)$ \\
Urinary incontinence & $2(1.6)$ \\
Injury of the bladder wall & $1(0.8)$ \\
Injury of the ureteral orifice & \\
Grade II & $5(3.9)$ \\
Hyperthermia & $10(7.8)$ \\
Clot retention & \\
Grade IIIa & $0(0)$ \\
Blood transfusion & $8(6.3)$ \\
Urinary retention & \\
Grade IIIb & $6(4.7)$ \\
Bladder tamponade & $5(3.9)$ \\
Repeat morcellation & \\
Grade IV & $0(0 \%)$ \\
TURP syndrome &
\end{tabular}

TURP syndrome $=$ transurethral resection of the prostate syndrome. neck: in 1 year after the surgery the stricture of the urethra occurred in $1(0.8 \%)$ patient, by the 3rd year this number increased up to $3(2.4 \%)$ patients, and by the 5th postoperative year, this complication was found in 4 (3\%) patients. A possible reason for the increase in strictures over time, according to Seki and colleagues, ${ }^{16}$ is the usage of a largediameter resectoscope-from 26F (to facilitate the morcellation process). Park and colleagues ${ }^{17}$ suggested that aggressive manipulations with the resectoscope in large prostates, can also be the reason for the stricture. On the contrary, Elkoushy and colleagues show that this type of complication occurs more often during the surgeries on the prostates of smaller volume. ${ }^{13}$ We were unable to find any correlation between stricture rates and the size of the prostate $(p=0.57)$. As for BNS, by the end of the 1 st year of surveillance it was found in $1(0.8 \%)$ patient, during the 3 rd year of surveillance-in $2(1.6 \%)$ patients; by the end of the 5 th year of surveillance the number of the patients remained the same. Krambeck and colleagues ${ }^{18}$ found the percentage of BNS to also change with time: 0 cases-in the first 6 months, $7(0.8 \%)$ cases (of 837 patients) - from 6 to 12 months, $4(1.3 \%)$ (in 314 patients) cases-between the 1st and 5th year of surveillance after the surgery, and $5(6 \%)$ cases-in 83 patients after 5 years of surveillance. Notably, BNS was

\section{Table 5. Delayed Postoperative Complications}

\begin{tabular}{|c|c|c|c|c|}
\hline $\begin{array}{l}\text { Type of } \\
\text { complication }\end{array}$ & $\begin{array}{l}\text { Postoperative } \\
\text { period, } \\
\mathrm{n}(\%)\end{array}$ & $\begin{array}{c}\text { In } 1 \\
\text { year } \\
\text { after the } \\
\text { surgery, } \\
\mathrm{n}(\%)\end{array}$ & $\begin{array}{c}\text { In } 3 \\
\text { years } \\
\text { after the } \\
\text { surgery, } \\
\mathrm{n}(\%)\end{array}$ & $\begin{array}{c}\text { In } 5 \\
\text { years } \\
\text { after the } \\
\text { surgery, } \\
\mathrm{n}(\%)\end{array}$ \\
\hline $\begin{array}{l}\text { Urethral } \\
\text { stricture }\end{array}$ & $0(0)$ & $1(0.8)$ & $3(2.4)$ & $4(3)$ \\
\hline $\begin{array}{l}\text { Bladder neck } \\
\text { sclerosis }\end{array}$ & $0(0)$ & $1(0.8)$ & $2(1.6)$ & $2(1.6)$ \\
\hline Repeat surgery & & & $1(0.8)$ & $4(3)$ \\
\hline
\end{tabular}


encountered in the patients with the mean mass of the enucleated tissue of $38.5 \mathrm{gr}$ (the same value is for the whole population in the study-76 gr). In Elkoushy and colleagues ${ }^{13}$ BNS of the bladder neck was associated with the size of the gland $(p=0.02)$, although we did not observe this correlation $(p=0.16)$.

We also reported complications during the early postoperative period. The quality of life after surgery is affected by SUI. On the 1st day after the removal of the catheter, SUI was found in $7(5.5 \%)$ patients. After 3 months, this number reduced to $5(3.9 \%)$ patients, and by the 6th postoperative month, urinary incontinence only occurred in $2(1.6 \%)$ patients. Possible mechanisms of SUI occurrence after HoLEP were described by Krambeck and colleagues $^{18}$ : (1) dysfunction of urethral sphincter because of its stretch during the operational intervention, despite the preservation of the anatomic consistency; this mechanism is also aggravated by the removal of the mucosa above the sphincter during performing of a three-lobe technique of enucleation; (2) Stress-induced hyperactivity of the bladder, which resolves with time. Normally, stress incontinence resolves during the first 6 to 12 months. In a study by Chen and colleagues, ${ }^{19}$ of 140 patients in the HoLEP group, SUI occurred in $13(9.2 \%)$ patients, which resolved in all the patients by the 6th postoperative month; while in Gong and colleagues, ${ }^{20} 3$ cases of SUI resolved by the 3rd postoperative month.

One of the most important parameters of the efficacy of the operation is functional improvement: PVR reduced by $39 \mathrm{~mL}(53.4 \%)$, Qmax increased by $12.1 \mathrm{~mL} / \mathrm{sec}(157 \%)$, and the results of IPSS and QoL improved by $73 \%$ and $57.5 \%$, respectively, compared with the preoperative values. It should be noted that the comparison of the results during the periods between years 1 and 3 , and between years 1 and 5 revealed progressive statistically significant worsening in these parameters (Table 2); however, in a 5-year period, the results remained within the reference values: IPSS -6.2 points, QoL -1.7 points, and Qmax $-19.8 \pm 5.1 \mathrm{~mL} / \mathrm{sec}$, PVR-34.1 mL. Similar tendency to worsening of the parameters was noted in the works by Gilling and colleagues $^{21}$ and Kuntz and colleagues ${ }^{22}$

\section{Limitations}

Among the main limitations of the study was its retrospective character and relatively small number of participants. Due to the retrospective type of the study, we were unable to collect some important data, for example, time from surgery to $\alpha$-blockers administration, or rate of urge incontinence. The majority of patients were excluded from the study due to data missing because of long follow-up. However, we are presenting only the data on those who were followed up to 5 years, which makes the data more valuable. Additionally, 127 patients in the final sample allow us to make statistically valid conclusions. Despite the singlecenter design of the study, we believe that participation of different surgeons who were employing a different technique makes the data more representative.

\section{Conclusion}

The improvement of the parameters during the early postoperative period after performance of HoLEP remains within a 5-year period. PVR, Qmax, IPSS, QoL, long-term complications, and the number of repeat operations does not depend on the age of the patients or the initial volume of the prostate.

\section{Ethics Approval}

The study was approved by the Sechenov University's (Moscow, Russia) Institutional Review Board.

\section{Informed Consent}

Informed consent was obtained from all individual participants included in the study.

\section{Author Disclosure Statement}

No competing financial interests exist.

\section{Funding Information}

No funding was received for this article.

\section{References}

1. Fraundorfer MR, Gilling PJ. Holmium:YAG laser enucleation of the prostate combined with mechanical morcellation: Preliminary results. Eur Urol 1998;33:69-72.

2. Huang SW, Tsai CY, Tseng CS, et al. Comparative efficacy and safety of new surgical treatments for benign prostatic hyperplasia: Systematic review and network meta-analysis. BMJ 2019;367:115919.

3. Li M, Qiu J, Hou Q, et al. Endoscopic enucleation versus open prostatectomy for treating large benign prostatic hyperplasia: A meta-analysis of randomized controlled trials. PLoS One 2015;10:1-14.

4. Gravas S, Cornu JN, Gacci M, et al. EAU Guidelines. Presented at the EAU Annual Congress, Amsterdam, The Netherlands. 2020.

5. Foster HE, Dahm P, Kohler TS, et al. Surgical management of lower urinary tract symptoms attributed to benign prostatic hyperplasia: AUA guideline amendment 2019. J Urol 2019;202:592-598.

6. Cornu JN, Ahyai S, Bachmann A, et al. A systematic review and meta-analysis of functional outcomes and complications following transurethral procedures for lower urinary tract symptoms resulting from benign prostatic obstruction: An update. Eur Urol 2015;67:1066-1096.

7. Herrmann TRW. Enucleation is enucleation is enucleation is enucleation. World J Urol 2016;34:1353-1355.

8. Enikeev D, Taratkin M, Laukhtina E, et al. En bloc and twolobe techniques for laser endoscopic enucleation of the prostate: Retrospective comparative analysis of peri- and postoperative outcomes. Int Urol Nephrol 2019;51:1969-1974.

9. Naspro R, Sancha FG, Manica M, et al. From 'gold standard' resection to reproducible 'future standard' endoscopic enucleation of the prostate: What we know about anatomical enucleation. Minerva Urol Nefrol 2017;69: 446-458.

10. World Health Organization. World Report on Ageing and Health, 2015;300.

11. Enikeev D, Glybochko P, Rapoport L, et al. A randomized trial comparing the learning curve of 3 endoscopic enucleation techniques (HoLEP, ThuFLEP, and MEP) for BPH using mentoring approach-Initial results. Urology 2018; 121:51-57. 
12. Enikeev D, Glybochko P, Okhunov Z, et al. Retrospective analysis of short-term outcomes after monopolar versus laser endoscopic enucleation of the prostate: A single center experience. J Endourol 2018;32:417-423.

13. Elkoushy MA, Elshal AM, Elhilali MM. Reoperation after holmium laser enucleation of the prostate for management of benign prostatic hyperplasia: Assessment of risk factors with time to event analysis. J Endourol 2015;29:797-804.

14. Han HH, Ko WJ, Yoo TK, et al. Factors associated with continuing medical therapy after transurethral resection of prostate. Urology 2014;84:675-680.

15. Strope SA, Vetter J, Elliott S, Andriole GL, Olsen MA. Use of medical therapy and success of laser surgery and transurethral resection of the prostate for benign prostatic hyperplasia. Urology 2015;86:1115-1122.

16. Seki N, Mochida O, Kinukawa N, Sagiyama K, Naito S. Holmium laser enucleation for prostatic adenoma: Analysis of learning curve over the course of 70 consecutive cases, $\mathbf{J}$ Urol 2003;170:1847-1850.

17. Park J, Kim JY, You JH, et al. Effect of preoperative urethral dilatation on preventing urethral stricture after holmium laser enucleation of the prostate: A randomized controlled study. Can Urol Assoc J 2019;13:E357-E360.

18. Krambeck AE, Handa SE, Lingeman JE. Experience with more than 1,000 holmium laser prostate enucleations for benign prostatic hyperplasia. J Urol 2010;183:1105-1109.

19. Chen YB, Chen Q, Wang Z, et al. A prospective, randomized clinical trial comparing plasmakinetic resection of the prostate with holmium laser enucleation of the prostate based on a 2-year followup. J Urol 2013;189:217-222.

20. Gong YG, He DL, Wang MZ, et al. Holmium laser enucleation of the prostate: A modified enucleation technique and initial results. J Urol 2012;187:1336-1340.

21. Gilling PJ, Wilson LC, King CJ, Westenberg AM, Frampton CM, Fraundorfer MR. Long-term results of a randomized trial comparing holmium laser enucleation of the prostate and transurethral resection of the prostate: Results at 7 years. BJU Int 2012;109:408-411.

22. Kuntz RM, Lehrich K, Ahyai SA. Holmium laser enucleation of the prostate versus open prostatectomy for prostates greater than 100 grams: 5-Year follow-up results of a randomised clinical trial. Eur Urol 2008;53:160-168.

Address correspondence to: Dmitry Enikeev, $M D$ Institute for Urology and Reproductive Health Sechenov University 2/1 Bolshaya Pirogovskaya Street Moscow 119991 Russian Federation

E-mail: dvenikeev@gmail.com

Abbreviations Used
$\mathrm{BNS}=$ bladder neck sclerosis
$\mathrm{BPH}=$ benign prostatic hyperplasia
$\mathrm{EEP}=$ endoscopic enucleation of the prostate
$\mathrm{HoLEP}=$ holmium laser enucleation of the prostate
$\mathrm{IPSS}=$ International Prostate Symptom Score
$\mathrm{LUTS}=$ lower urinary tract symptoms
$\mathrm{PSA}=$ prostate-specific antigen
$\mathrm{PVR}=$ postvoid residual
$\mathrm{Qmax}=$ maximal flow rate
$\mathrm{QoL}=$ quality of life in connection with the present
$\mathrm{SUI}=$ stress urinary incontinence
$\mathrm{TURP}=$ Transurethral Resection of the Prostate
syndrome $\quad$ Syndrome
$\mathrm{V}=$ prostatic volume

